\title{
CHARACTERIZATIONS OF A MULTIVARIATE EXTREME VALUE DISTRIBUTION
}

\author{
RINYA TAKAHASHI, * Kobe University of Mercantile Marine
}

\begin{abstract}
Characterizations of a multivariate extreme value distribution in terms of its marginals are established.
\end{abstract}

UNIVARIATE MARGINALS; DEPENDENCE FUNCTION

In this note we shall characterize a $k$-dimensional extreme value distribution in terms of its univariate marginals. For details of the multivariate extreme value distributions, see Galambos (1978), Chapter 5.

Theorem. Let $H$ be a $k$-dimensional extreme value distribution with univariate marginals $H_{i}, i=1, \ldots, k$.

(a) We have

$$
H(\boldsymbol{x})=H_{1}\left(x_{1}\right) \cdots H_{k}\left(x_{k}\right) \text { for all } \boldsymbol{x}=\left(x_{1}, \ldots, x_{k}\right) \in \boldsymbol{R}^{k}
$$

iff there exists $\boldsymbol{p}=\left(p_{1}, \ldots, p_{k}\right) \in \boldsymbol{R}^{k}$ such that $0<H_{i}\left(p_{i}\right)<1, i=1, \ldots, k$ and

$$
H(\boldsymbol{p})=H_{1}\left(p_{1}\right) \cdots H_{k}\left(p_{k}\right) \text {. }
$$

(b) We have

$$
H(\boldsymbol{x})=\min \left\{H_{1}\left(x_{1}\right), \ldots, H_{k}\left(x_{k}\right)\right\} \quad \text { for all } \boldsymbol{x} \in \boldsymbol{R}^{k}
$$

iff there exists $p \in R^{k}$ such that

$$
0<H_{1}\left(p_{1}\right)=\cdots=H_{k}\left(p_{k}\right)<1 \text { and } H(\boldsymbol{p})=H_{1}\left(p_{1}\right) .
$$

Proof. (a) The proof of this part is similar to that of Theorem 2.2 of Takahashi (1987) and is omitted.

(b) Necessity is obvious so that we shall prove sufficiency. Let $D_{H}(y)=$ $H\left(H_{1}^{-1}\left(y_{1}\right), \ldots, H_{k}^{-1}\left(y_{k}\right)\right), y \in(0,1)^{k}$, be the dependence function of $H$, where $H_{i}^{-1}$ is the generalized inverse of $H_{i}, i=1, \ldots, k$. Then we have the following results:

(1) $D_{H}^{s}\left(y^{1 / s}\right)=D_{H}(y)$ for all $s>0$. (See Lemma 5.4.1 of Galambos (1978).)

(2) If $y \leqq y^{\prime}$, then $D_{H}(y) \leqq D_{H}\left(y^{\prime}\right)$.

(3) If $H^{\prime}$ is an extreme value distribution such that $H_{i}^{\prime}=H_{i}, i=1, \ldots, k$, then $H(x) \leqq H^{\prime}(x)$ for all $\boldsymbol{x} \in \boldsymbol{R}^{k}$ iff $D_{H}(\boldsymbol{y}) \leqq D_{H^{\prime}}(\boldsymbol{y})$ for all $\boldsymbol{y} \in(0,1)^{k}$.

Suppose the given sufficiency condition holds. Then we have

$$
D_{H}(c \mathbf{1})=c,
$$

Received 16 June 1967; revision received 8 October 1987.

* Postal address: Department of Applied Mathematics, Kobe University of Mercantile Marine, Fukae-Minami, Higashinada, Kobe 658, Japan. 
where $c=H_{1}\left(p_{1}\right)$ and $1=(1, \ldots, 1)$. The proof will be completed if we show $D_{H}(y)=$ $\min \left\{y_{1}, \ldots, y_{k}\right\}$. For any $y \in(0,1)$ there exists an $s>0$ such that $y^{1 ; s}=c$. Hence, by (1) and (4)

$$
D_{H}(y \mathbf{1})=D_{H}^{s}\left(y^{1 / s} \mathbf{1}\right)=\left(y^{1 / s}\right)^{s}=y .
$$

Let $y=\left(y_{1}, \ldots, y_{k}\right)$ and $y=\min \left\{y_{1}, \ldots, y_{k}\right\}$, then by (2), (3), (5) and Theorem 5.4 .1 of Galambos (1978), we have

$$
y=D_{H}(y \mathbf{1}) \leqq D_{H}(y) \leqq \min \left\{y_{1}, \ldots, y_{k}\right\}=y .
$$

\section{References}

Galambos, J. (1978) The Asymptotic Theory of Extreme Order Statistics. Wiley, New York.

TAKAHASHI, R. (1987) Some properties of multivariate extreme value distributions and multivariate tail equivalence. Ann. Inst. Statist. Math. To appear. 